\title{
RESTful Web Service as Data Generator for Reporting of Academic Information System
}

\author{
M. Miftakul Amin ${ }^{1, *}$ Slamet Widodo ${ }^{1}$ Adi Sutrisman ${ }^{1}$ Ervi Cofriyanti ${ }^{1}$ Ali Firdaus ${ }^{1}$ \\ ${ }^{1}$ Department of Computer Engineering, Politeknik Negeri Sriwijaya, Jl. Srijaya Negara Bukit Besar, Palembang, \\ 30139, Indonesia \\ ${ }^{*}$ Corresponding author. Email: miftakul_a@polsri.ac.id
}

\begin{abstract}
The academic information system in higher education is a system that has an important role in higher education operations. Interoperability between academic information system is needed to bridge the exchange of data and information in heterogeneous environments, where systems are developed using different programming languages, database management systems, operating systems, and network operating systems. This study proposes a model for reporting academic information using the RESTful web service as a data generator to present data that can be consumed for various applications that can be run on desktop applications, web applications, and mobile applications. Based on the test results, the results show that the methods in the RESTful web service can be consumed properly and show the expected performance.
\end{abstract}

Keywords: Interoperability, RESTful web service, data generator

\section{INTRODUCTION}

Academic information system is an information system that has several system functions, including processing student data, lecturer data, student administration, attendance of lecturers and students, class schedules, value data, and several other important functions related to the learning process in higher education[1]. Information needs that can be accessed through various kinds of hardware and various kinds of applications are needed to increase the functionality of academic information systems. So far, the provision of academic data and information occurs in only one application platform and there are no data and information services that can be accessed widely and across platforms. Several attempts to improve the performance of academic information systems include implementing Enterprise Architecture Planning (EAP) [2] and adding features of decision support systems [3].

This study aims to provide a RESTful web service that can be used as a data generator to generate data in the form of JSON data, then the JSON data can be consumed and used as data / information by several applications such as web applications, desktop applications, and mobile applications. The JSON data format was chosen because it is compatible with several programming languages, database management systems, and even different operating systems. RESTful web service has provided a number of standard methods such as GET, POST, PUT, and DELETE which are equivalent to Create, Read, Update, and DELETE (CRUD) operations, so that they can be easily implemented in various application platforms.

\section{LITEARUTER REVIEW}

\subsection{Service Oriented Architecture (SOA)}

SOA implementation using web services is an appropriate framework for integrating data and applications in an organization [4]. Integration is done by collecting data from a variety of different sources and is generally done in real-time. It should be noted in the integration process is the difference in the format and structure of the data owned by the data source. SOA allows the reuse of software components, provides independent protocols, and facilitates application integration.

In the context of data and information exchange the integration process can be carried out with open standards [5]. This mechanism can be done with XML and SOAP or RESTful web service. SOA provides an interoperability mechanism for accessing services on different operating system platforms and programming languages, thus enabling cross-platform communication. At a higher level, SOA can be used to integrate business 
process organizations [6]. Integration can also be carried out both intra and between health care service organizations [7]. SOA's role is to publicize business functions by being programmed and accessed as a service [8]. SOA framework is built using several principles including:

- A business function is divided into several smaller functions and can be reused using the concept of modularization.

- Communication between client and server is done loosely coupled.

- The encapsulation concept is used to wrap business functions.

So by using some of these principles, the framework is easily integrated into third party software and can be accessed in a distributed environment. The SOA framework involves 3 roles, namely service broker, service provider, and service requester [9]. Generally SOA architecture can be seen in Figure 1.

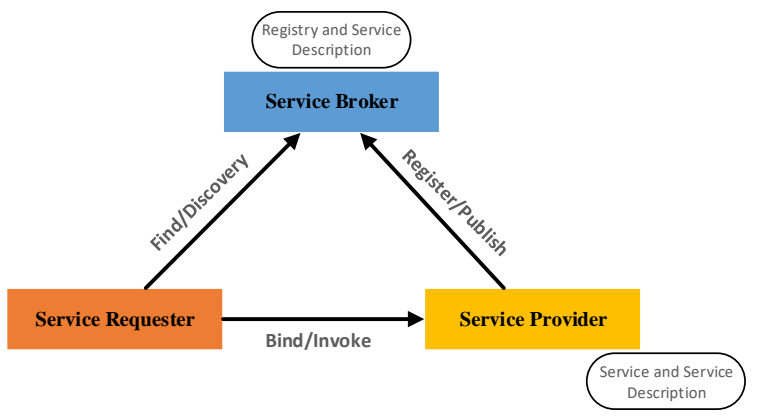

Figure 1 The SOA Framework

\subsection{Interoperability}

Interoperability is defined as the ability of two or more systems or components to exchange information and to use the information that has been exchanged [10]. The data format that is exchanged has an important role in interoperability. The data format commonly used is XML [11]. The lack of interoperability in computing is a major challenge both academically and industrially. Although there is already a standard data exchange format, it still requires an in-depth study because it is implemented in heterogeneous ecosystems [12]. There are 3 layers to implement interoperability, namely syntactic, semantic, and process, as can be seen in Figure 2. Syntactic interoperability refers to the data exchange format. Semantic interoperability refers to the mapping of data structures from various sources. Spread process interoperability refers to business processes and workflows between health care organizations [13].

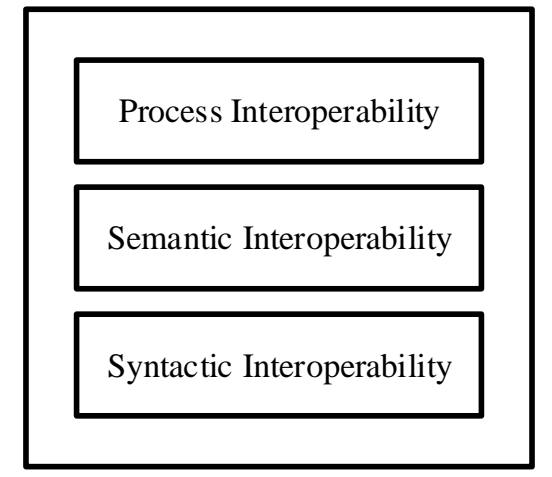

Figure 2 Architecture of Interoperability Layers

\subsection{Web Service}

A web service consists of a service and service description in the form of a software module provided by a service provider, and it is accessed through the internet network [14]. Web service is accessed by running an existing method on a server through a client application, and are free from platform limitations to create interoperability between applications [15]. Web services can also be used to integrate applications from various sources into an application software. Moreover, web services can be run in a distributed environment [16]. With these characteristics, the SOA concept can be realized using Web Service technology.

\subsection{RESTful Web Service}

RESTful Web service is an architecture consisting of components, connectors, and data elements in a distributed environment. REST can be identified using URIs and some HTTP methods that can be easily used by programmers [17]. REST is an alternative to web service development in addition to use SOAP, to support machine-to-machine interoperability through the internet [18]. To access and execute URIs, the RESTful web service uses several main methods such as POST, GET, PUT, and DELETE [19]. The four HTTP methods are equivalent to CRUD operations on a database management system (DBMS) [20] [21]. CRUD operation is the ability to interact with databases such as adding, reading, correcting, and deleting data. As it is known that DBMS can act as Passive Database and Active Database [22]. RESTful web services can act as interfaces and APIs to be accessed from client applications [23]. The conceptual model of REST can be seen in Figure 3. 


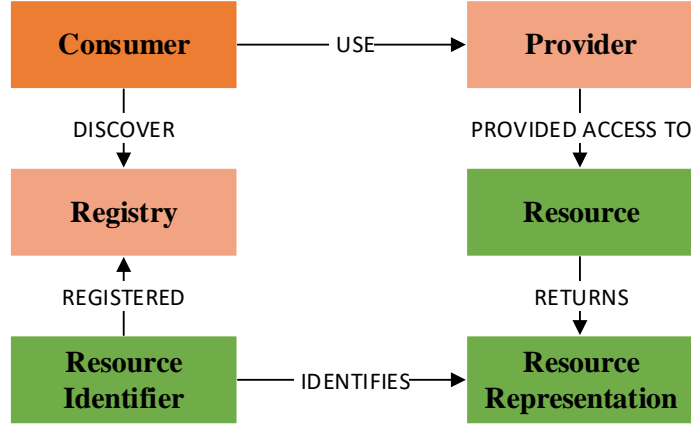

Figure 3 RESTful Conceptual Model

The data format that is commonly used in RESTful web services is JSON as the data format that is transmitted [24]. This JSON data format is lighter than the XML data format, and is easy to read for both humans and software. JSON uses key-value pairs to describe data structures. Web applications in general can be used for increase automation, information processing, and improve interactions and collaboration among information systems [25] [26].

\section{IMPLEMENTATION AND RESULTS}

The architecture was built using the CodeIgniter framework version 3.1.2 with the addition of CodeIgniter Rest Server.

\subsection{Testing Using POSTMAN Software}

POSTMAN software can be used to test the methods made. With a simple and easy-to-understand interface, POSTMAN can provide information on whether the RESTful web service created has succeeded in providing the system performance as expected. Figure 4 Is a display of testing using POSTMAN software.

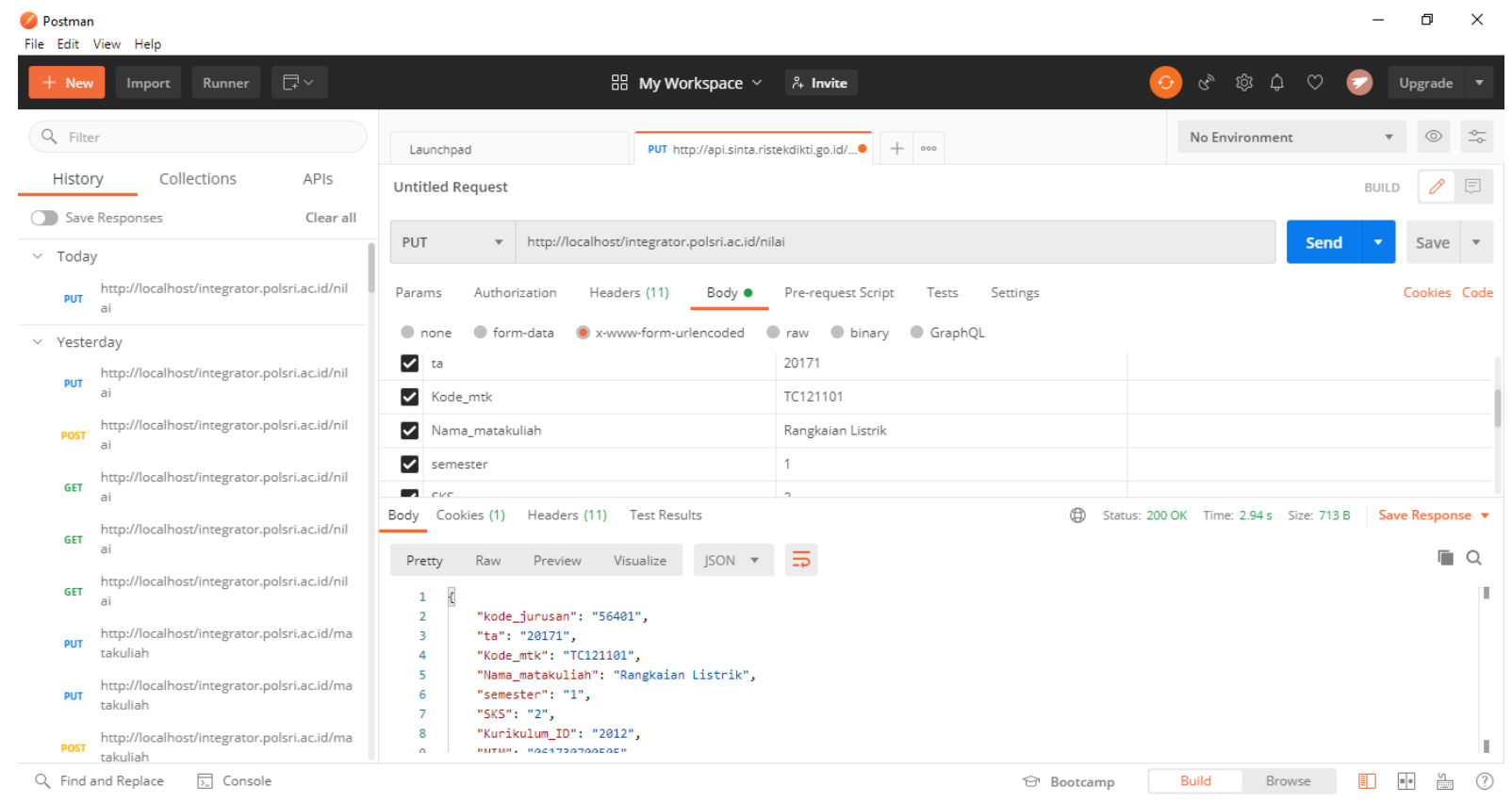

Figure 4 Display Performance Testing System Using POSTMAN

The data generated from calling the RESTful web service method will then be displayed in the data in the JSON format, and can then be used by various applications to exchange data and information across platforms.

\subsection{Performance of RESTful Web Service}

Performance testing was done by calculating the response time provided by the RESTful web service framework, to access various services provided via the HTTP method as shown in Table 1. Testing was done by sending and receiving a number of data payloads in
JSON data format, and calculated how long the system provide a response to complete the service.

Table 1 Performance Measurement Results of RESTful Web Services

\begin{tabular}{|l|l|r|r|}
\hline No. & Method & $\begin{array}{r}\text { Pyload } \\
\text { Bytes })\end{array}$ & $\begin{array}{r}\text { Time } \\
\text { (Milliseconds) }\end{array}$ \\
\hline 1. & GET & 663 & 53 \\
\hline 2. & POST & 569 & 98 \\
\hline 3. & PUT & 440 & 42 \\
\hline 4. & DELETE & 394 & 45 \\
\hline
\end{tabular}




\begin{tabular}{|l|l|r|r|}
\hline 5. & GET & 325 & 55 \\
\hline 6. & POST & 1200 & 154 \\
\hline 7. & PUT & 950 & 175 \\
\hline 8. & DELETE & 395 & 52 \\
\hline 9. & GET & 3592 & 1278 \\
\hline 10. & POST & 1543 & 125 \\
\hline 11. & PUT & 1654 & 145 \\
\hline 12. & DELETE & 1367 & 122 \\
\hline 13. & GET & 913 & 67 \\
\hline 14. & POST & 764 & 66 \\
\hline 15. & PUT & 636 & 45 \\
\hline 16. & DELETE & 521 & 40 \\
\hline 17. & GET & 1780 & 76 \\
\hline 18. & POST & 816 & 56 \\
\hline 19. & PUT & 687 & 47 \\
\hline 20. & DELETE & 523 & 42 \\
\hline 21. & GET & 591 & 47 \\
\hline 22. & POST & 713 & 84 \\
\hline 23. & PUT & 585 & 50 \\
\hline 24. & DELETE & 425 & 48 \\
\hline
\end{tabular}

\section{CONCLUSION}

In this research an attempt is made to provide data generator through the SOA approach using RESTful web service technology. These are some conclusions:

- RESTful web service can be used to build crossplatform applications in order to realize interoperability between applications that are built on different platforms.

- The process of sending and accessing messages that can be done by sending requests via the HTTP method that consists of POST, PUT, GET, and DELETE.

- The process of reporting system can be done by running several methods that have been provided by RESTful web service as an Application Programming Interface (API).

\section{REFERENCES}

[1] B. Kurniawan, Integrated Information System for Radio Frequency Identification Based Administration and Academic Activities on Higher Education IOP Conf. Ser.: Materi. Sci. Eng. 2018, 407012097

[2] Y. Sumaryana, A. Sudiarjo, Academic Information System Architecture Planning at the Perjuangan University Tasikmalaya Using EAP J. Phys.: Conf. Ser. 2020, 1477032026

[3] T. Hidayat et al, Design information system of registration and scheduling information laboratory of information systems and the decision of Bandung Islamic University J. Phys.: Conf. Ser. 2020, 1469012134

Figure 5 provides the RESTful web service performance information in graphical form. From Figure 5 it can be seen that the system performance can run stably, marked by a relatively fast response time even with a large payload size. This can be seen in service numbers $6,9,10,11,12$, and 17. System performance is influenced by the capacity of data transmitted (payload), the size of the bandwidth, and hardware specifications used by the system.

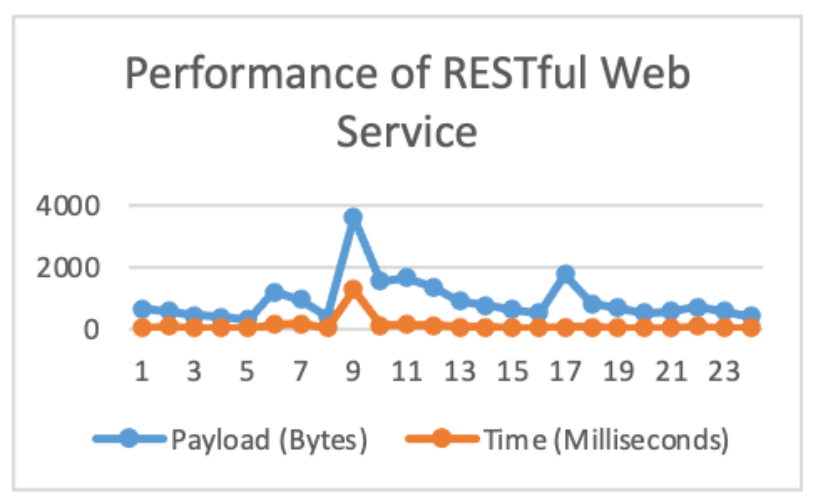

Figure 5 Processing Graph Services

[4] Bakar M S A, Ta'a A, Hashim K F., Information Integration in Electronic Health Information Systems using Service Oriented Architecture Approach ARPN Journal of Engineering and Applied Sciences, 2015, 10(2): 549-556

[5] Ismael S N, Mohd O, Rahim Y A., Implementation of Open Data in Higher Education: A Review Journal of Engineering Science and Technology, 2018, 13(11): 3489-3499

[6] Paul A., Paul V., A Framework for e-Government Interoperability in Indian Perspective, International Journal of Computer Information Systems and Industrial Management Applications, 2014, 6(1): $582-591$

[7] Batra U, Mukharjee S., National Healthcare Information System Integration: A Service Oriented Approach International Journal of Computers, 2011, 3(5): 354-361

[8] Wei, N., Research on an Information Application Integration Platform Based on SOA and Web 
Service International Journal of Multimedia and Ubiquitous Engineering, 2015, 10(12): 165-174.

[9] Amin M M, Sutrisman A, Stiawan D, Ermatita, Maseleno A., Design restful web service of national population database for supporting ehealth interoperability service Journal of Theoretical and Applied Information Technology, 2018, 96(15): 4794-4805.

[10] Geraci A, McMonegal L, Meyer B, Lane J, Wilson P, Radatz J, Yee M, Porteous F, SpreengSteel F. IEEE Standard Computer Dictionary: Compilation of IEEE Standard Computer Glossaries. 1991, IEEE Press.

[11] Wasala A, Buckley J, Schaler R, Exton C., An Empirical Framework for Evaluating Interoperability of Data Exchange Standards based on Their Actual Usage: A Case Study on XLIFF Computer Standards \& Interface, 2015, 42(1): 157-170.

[12] Selway M, Stumptner M, Meyer W, Jordan, A. (in press). A Conceptual Framework for Large-Scale Ecosystem Interoperability and Industrial Product Lifecycles, Data \& Knowledge Engineering.

[13] Garai, A., Comphrehensive Healthcare Interoperability Framework Integrating Telemedicine Consumer Eletronics with Cloud Architecture, in: IEEE $15^{\text {th }}$ International Symposium on Applied Machine Intelligence and Informatics, Herl'any, Slovakia, 2017, 411-416.

[14] Tihomirovs J, Grabis, J., Comparison of SOAP and REST based Web Services Using Software Evaluation Metrics, Information Technology and Management Science, 2016, 19(1): 92-107.

[15] Elia I A, Laranjeiro N, Vieira M., Understanding Interoperability Issues of Web Service Frameworks, in: $44^{\text {th }}$ Annual IEEE/IFIP International Conference on Dependable Systems and Networks, Atlanta, USA, 2014, pp. 323-330.

[16] Sirisha K L S, Kumar V S., Role of Web Services in Distributed Heterogeneous Applications and Testing for Quality Assurance, International Journal of Emerging Trends \& Technology in Computer Science (IJETTCS), 2017, 6(6): 100-103

[17] Anika S, Pai V, Sudhindra R., RESTful Web Services, International Journal of Advanced Information Science and Technology (IJAIST), 2014, 3(4): 13-16.
[18] Warvante, M.S., A Survey on Developing Web Services with SOAP and REST, International Journal of Advanced Research in Computer and Communication Engineering, 2017, 6(10): 118124.

[19] Naidu J, Kumar S H C., Implementation of Document Envelope REST APIS for B2B Sterling Integrator, International Journal for Research in Applied Science \& Engineering Technology (IJRASET), 2017, 5(6): 356-365.

[20] Halili F, Ramadani, E., Web Services: A Comparison of SOAP and REST Services, Modern Applied Science, 2018, 12(3): 175-183.

[21] Miftakul Amin M, Maseleno A, Shankar K, Perumal E, Vidhyavathi R.M, Lakshmanaprabu S K., Active database system approach and rule based in the development of academic information system, International Journal of Engineering and Technology (UAE), 2018, 7(2.26): 95-101.

[22] Rathod, D., Performance Evaluation of RESTful Web Services and SOAP/WSDL Web Services, International Journal of Advanced Research in Computer Science, 2017, 8(7): 415-420.

[23] Mumbaikar S, Padiya, P., Web Services based on SOAP and REST Principles. International Journal of Scientific and Research Publications, 2013, 3(5): $1-4$.

[24] Grigorova K, Mironov, K., The Art of Fast web: Reducing the size of RESTful web services response, International Journal of Computer Science (IIJCS), 2015, 3(2): 5-10.

[25] Ashtari S, Danesh M, Shirgahi H., A Novel User Profile-Based Fuzzy Approach for Evaluating Trust in Semantic Web, IIUM Engineering Journal, 2019, 20(1): 158-176.

[26] M. Miftakul Amin, Adi Sutrisman, Deris Stiawan, Ermatita Ermatita, Mohammed Y. Alzahrani, Rahmat Budiarto, Interoperability framework for integrated e-health services, Bulletin of Electrical Engineering and Informatics (BEEI), vol. 9, no. 1, 2020,

pp. 